\title{
Wireless Charging of Electrical Vehicles
}

\author{
D. Sharmila, Vemula Venkata Sai Praveen Kumar
}

\begin{abstract}
A rapid increase in the population now a day's lead to a large necessity of transport, this made an increase in demand for the automobile industry. In today's world, life without these automobiles is unimaginable. A part of this automobile industry is transport usage which majorly consists of cars, buses and so on. All these need a huge amount of fuel in which we majorly use crude oil (petrol/diesel) and hence it has high demand and more usage. This leads to the extinction of the available resources on earth. So, the electric cars are introduced which runs on the batteries. A recent survey also showed that the usage of Electric Vehicles (EVs) is also increasing every year. As these batteries need to be recharged every time which takes a lot of time and as they are not capable of running over a long distance this increases Range-Anxiety another reason for the less usage of these electric cars is less availability of charging stations due to their high installation cost., so we are introducing a new technology where the cars can be automatically charged when they are in driving mode. This enables an increase in the usage of electric vehicles and provides environmental balance.
\end{abstract}

Keywords: Electric Vehicles, Combined Charging System, Charge De Move, Electronic Charging Stations, Vehicle Charging Unit, Base Charging Unit, Magnetic Resonance, Centre of gravity, Range Anxiety, Super Charging Stations, Plug-in Hybrid Electric Vehicles, Regenerative Breaking, Onboard controller.

\section{INTRODUCTION}

$\mathrm{T}$ he usage of the cars in the recent days has increased rapidly. This leads to a major usage of the fuel to run the cars, so Electric Vehicles were introduced but the power that is needed to charge these electric cars is insufficient, so to charge these electric cars charging stations are planned to build in order to increase the usage of Electric Vehicles, but a lot of time is being consumed in these stations to charge a car completely to 100 percent. There are chances that the car may even stop at any place as there are chances that the battery may drain at any time this may be very inconvenient for the users and also may create a huge delay to reach their

Another survey also refers that if the usage of the resources remains same the resources may one day become extinct and this may happen very soon. On an average a car needs over 120 -volt and 40amps output to recharge a car. Based on the capacity of the battery the time taken to charge a car also varies, it majorly varies around $30 \mathrm{~min}$ to 24 hours. To charge

Revised Manuscript Received on November 16, 2019

* Correspondence Author

Dr. D. Sharmila, Associate Professor, Dept. of Electronics \& Communication Engineering, R.M.D Engineering College, Tamil Nadu, India. Email: dsharmila25@gmail.com

Vemula Venkata Sai Praveen Kumar, Dept. of Electronics \& Communication Engineering,R.M.D Engineering College, Tamil Nadu, India Email: uec17432@rmd.ac.in destination.

these cars at home we need a separate charging point which is to be installed at the parking place. In case that you are going out for a long drive it would not be possible to take these set along with us to charge the car.

The main objective of this paper is to introduce a new method such that there is no need for the drivers to search for the charging stations when there are away from the car parking slots and far away from the charging stations. This also reduces the usage of the natural resources that are being used now a day for fuel. So that the natural resources consumption can be reduced to great extent and this also brings awareness in people that the increased usage of the smart cars reduces the greenhouse gases emission which an eco-friendly subscription.

All the major automobile industries are now a days working on the same problem, many companies stand in this list by the Tesla automobile Industry stands first in the list followed by The BMW Industry, Nissan, Ford and etc.,

\section{THE PRESENT WAYS OF CHARGING}

Now a day the Electric Vehicles need a very high voltage and current when compared to that of the household appliances that are being used. So, to charge these types of cars, a lot of current is needed which cannot be hold by the normal plugins that are used in the houses these days, so special kind of plugins are being used. Some of the charging systems that are used to charge a car are:

\section{TYPE-1}

It is a single-phase system which supports power levels up to $7.4 \mathrm{~kW}(230 \mathrm{~V}, 32 \mathrm{amps})$. It is most widely used in Asian regions. The current produced here is DC.

\section{TYPE-2}

It is a triple phase system which supports power levels up to $43 \mathrm{~kW}$ (400V,63amp). It is most widely used in European countries. The current produced here is AC.

\section{COMBINED CHARGING SYSTEM (CCS)}

This is an enhanced version of Type- 1 and Type- 2 . There are two power contacts for purpose of quick charging a supports AC and DC charging power levels. The charging levels of practical values are $50 \mathrm{~kW}$.

Majorly the CCS type of system is being used which allows the high voltage level of the DC charging that is on an average of 80-350 Watts. Almost all the major companies prefer this type of charging like Tesla, BMWand Jaguar and so on.

\section{CHADEMO CHARGING SYSTEM}

CHAdeMO (Charge de Move) Charging System which has power level of $50 \mathrm{~kW}$ by $500 \mathrm{v}$ and a current of 120Ampere. This uses DC fast charging technique. These mostly used in Japanese 


\section{Wireless Charging of Electrical Vehicles}

countries. In the latest update that is done in this technology is done by Japan the wattage is increased nearly 5times that is a version- 2 of CHAdeMO producing about $400 \mathrm{kw}$ by using $1000 \mathrm{v}$ and 400Ampere.

Based on the power source and the capacity of the car charging time varies by the current and voltage rating.

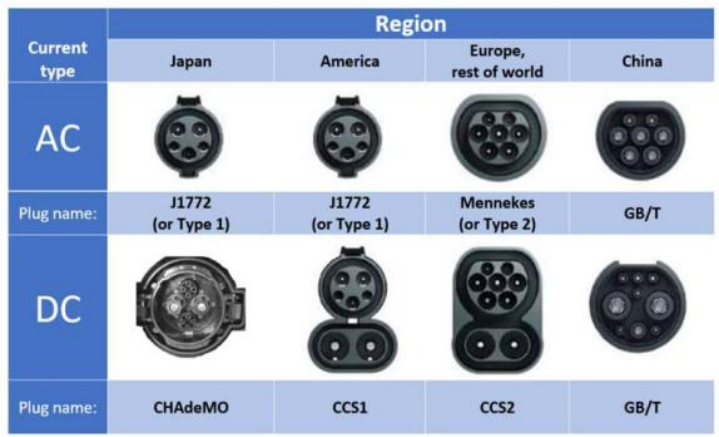

\section{WIRLESS CHARGING}

It is a difficult task to charge using the wired technology always so the wireless technology is introduced which consist of the components like

1. Power Supply

2. Base Pad

3. Wireless Power and Data Transfer

4. Vehicle Pad

5. On Board Controller

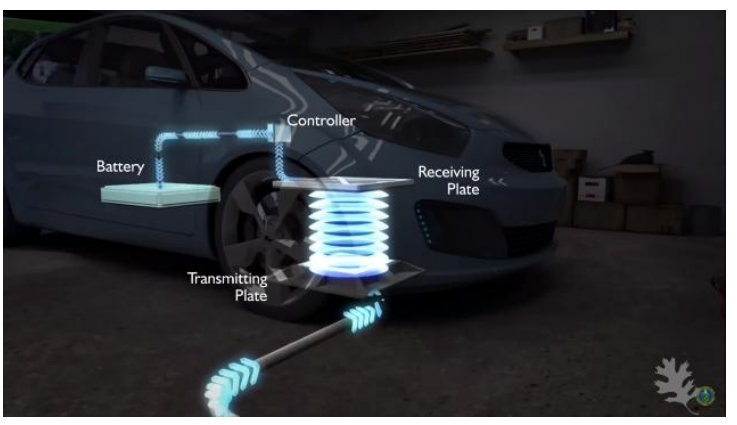

Here the MAGNETIC RESONANCE is used to couple the Base Charging Unit (BSC) to the Vehicle Charging Unit (VCU), this system can work at very low frequencies also. It can work below $100 \mathrm{KHZ}$ frequency also.

It can be used at the parking slots which is the easiest way. Here the DC-DC conversion of the charging is used. The efficiency of this charging is nearly $90 \%$. Using the Qualcomm Halo Wireless technology, an electronic vehicle can be charged with an efficiency of $97 \%$. The Alignment tolerance can also be maintained to a limited level of about $200 \mathrm{~mm}$. The size of VCU System is a smaller unit than that of the BCU System.

This system enables to place these pads at household, parking places, bus stops for electric buses to charge.

\section{CHARGING FROM ROADS}

For this Technique special kind of the roads are to be implemented so that the charging of the cars is possible even when we are driving.
The road is dug by machine and coils are laid inside the road; below cars the charging pads are present. The coils are electrified from nearby stations so that when a car passing on the coil through induction mechanism the car gets charged.

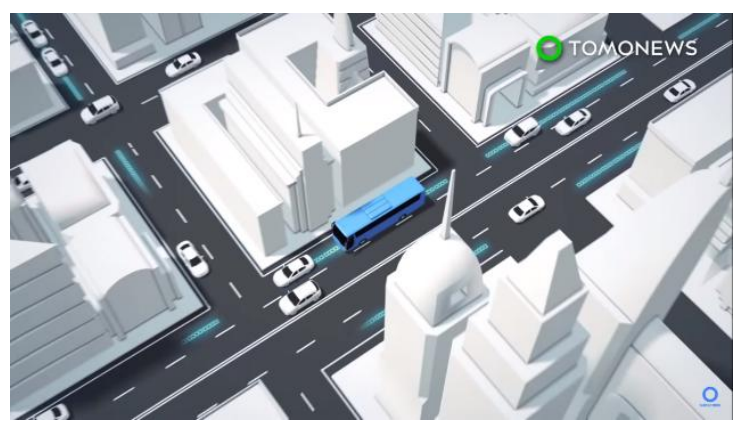

VII. SOLAR ROADS

This technique not only provides the current but also provides the digital driving services which can be remotely controlled.

These Solar Power Roads are majorly of 3 layers,

\section{$1^{\text {st }}$ Layer:}

Initially all the recyclable materials are placed on the ground which form the first layer this layer is generally known as the base layer.

$2^{\text {nd }}$ Layer:

This is present above first layer, which generally consists of the circuit where the light that is being emitted by the sun is converted into the electrical energy. It also consists of LED in for lighting for different purpose of need.

\section{$3^{\text {rd }}$ Layer:}

The third layer is the final layer consists of the reinforced glass with traction support for the wheels.

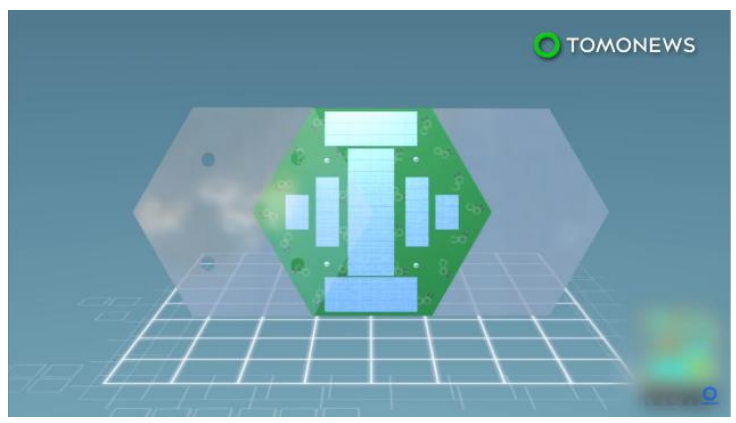

All these layers together can weigh about 250 thousand pounds of weight. In addition to these layers' temperature grid is also added in order to melt the ice that is useful to melt ice on roads in any present during winter season.

In France, by putting a step ahead they started using this electrical power generated to the house hold applications, nearly 4 meters of solar road can supply the power to one house.

\section{RESULTS AND DISCUSSIONS}

A recent survey has stated that the usage of the Electrical cars is being increased every year.

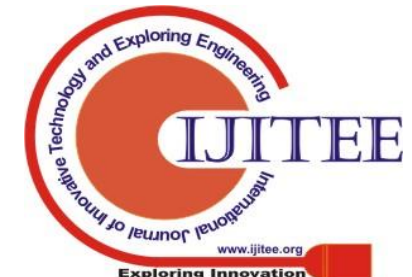




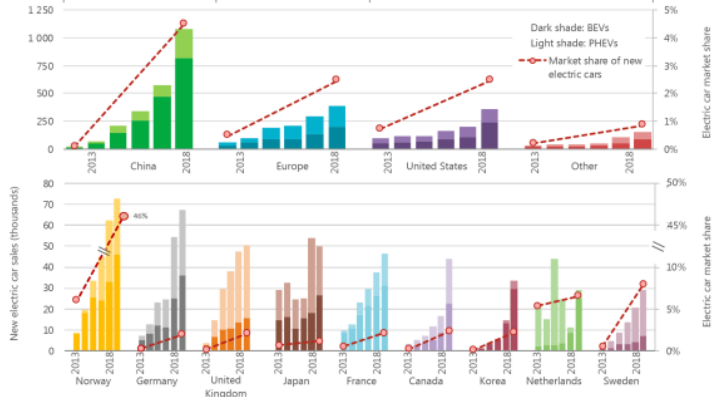

The above graph shows that the no. of consumers that are using the electrical cars form the year 2013-2018 have increased exponentially in every county.

This means that the consumption of the energy is also at a high rate, this leads to a large amount of electricity is needed by using the above technologies some of the problems can be solved.

As the car gets charged at motion the time that is used for the charging also decreases.

As the entire roads are altered these in no separate need to carry a power supply when the battery is down, it creates its own electrical energy with which it runs.

Usage of this kind of technologies have many advantages as mentioned below:

1. The cost for the running of cars decreases.

2. The no. of parts present in car are reduced when compared the number of parts present in the fuel cars- this makes them comparatively light weight

3. The cost of the cars also gets decreased.

4. Only a little service is needed whenever required.

5. The battery is provided with an 8years of warranty.

6. This also reduces the emission of the greenhouse gases like $\mathrm{CO} 2, \mathrm{CFCs}$ and so on.

7. Risk of the major fire accidents also reduces.

8. As conventional cars are noise producing machines Electrical cars are noise less this in turn reduces the noise pollution as well.

9. Electrical cars have low centre of gravity. So decreases the chance of roll over.

10. Electrical Vehicles have regenerative braking system thereby charges car while driving

11. On road charging decreases the range anxiety.

12. Cost per kilometre for electric vehicles is $1 / 3^{\text {rd }}$ of cost for petrol vehicles.

13. Use of more renewable resources by using solar roads reduces pollution by decreasing production in thermal power plants.

\section{FURTHUR MORE CHALLENGES}

1. Range anxiety is not yet solved charging through roads may increase drive to 5 to 10 miles at maximum.

2. Wireless charging of Qualcomm halo pads in parking places charging is more efficient only when the vehicle is parked for more time.

3. Increase in depth of discharge may decrease the battery cycles.

\section{PROPOSED IDEA}

Many researchers have been done for finding the reason of decreasing in capacity of battery as years pass by.

They came to a conclusion that the Depth of Discharge (DoD) decides the life time of the battery.

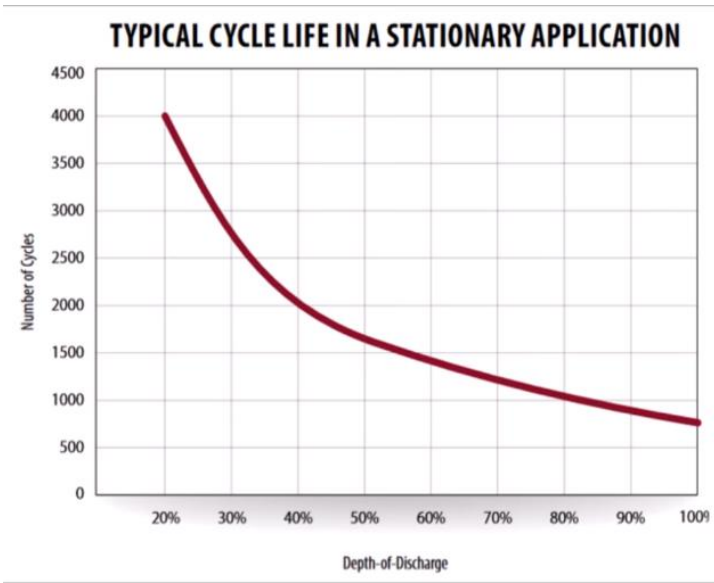

Above graph shows the decay of slope of decrease in number of cycles of the battery.

\section{DoD 20\% DoD 50\% DoD 100\% 4000 cycles 1600 cycles $\quad 800$ cycles}

So as to decrease the DoD and increase the number of cycles the battery must be discharged less. As the need of battery is more, consumption cannot be reduced. As the cost should be optimum, battery pack cannot be increased.

So, the idea of approach is, if the whole battery pack Is divided into smaller divisions of 3 to 4 packs and having a dedicated generator to a car with suitable algorithm all the problems can be resolved.

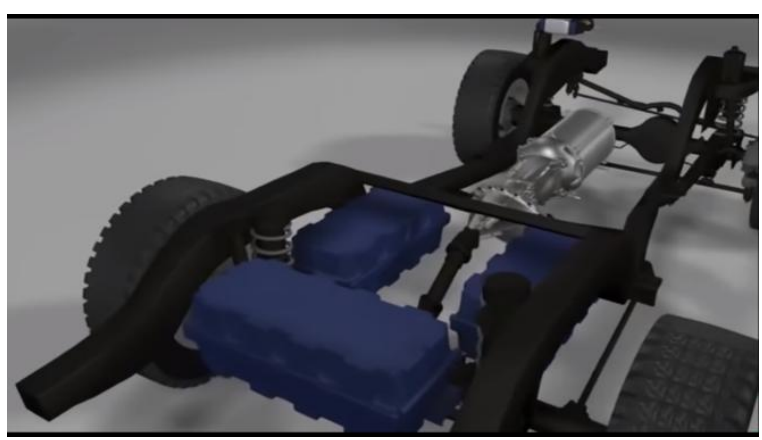

As in the above figure the battery pack is separated into three. A dedicated generator added to the car. Considering a battery is discharging for running the car as a dedicated generator present inside the car it continuously produces current and this can be used to 
charge other battery which is not under use.

An algorithm is designed in such a way that if a battery is discharged to certain level a battery pack which has higher current is switched to use and the battery pack with less charge will be charged using the generator.

This can be said as cyclic switching of battery charging and discharging which does not increase the cost but increases the efficiency of the car.

If this technique is implemented the battery life cycles will get increased by huge extent.

\section{REFERENCES}

1. Muhammad Aziz, Advanced Charging System for plug-in Hybrid Electric Vehicles.

2. Charging Electric Vehicles" as outlined by the Australian Electric Vehicles Association on website http://www.gumtree.com.au/scam-security-centre/ buying-on-gumtree/the-ltimate-electric-cars-buying-guide.

3. Electric Vehicle Range website https:// www.ergon.com.au / network / smarter-energy/electric-vehicles/electric-vehicle-range.

4. Other Vehicle Cost Factors on websitehttp://myelectriccar.com.au/ calculator.

5. Household Charging Infrastructure Costs website http://www.gumtree.com.au/scam-security-centre/buying-on-gumtree/theultimate-electric-cars-buying-guide.

6. Types of electric vehicles Website https://www.ergon com.au/network/smarter-energy/electric-vehicles/types-of-electric-vehicles.

7. Battery Storage website https://www.ergon.com. au/network/smarter-energy/battery-storage.

8. What are the driving benefits of an electric vehicle on website http://www.pge.com/en/myhome/saveenergymoney/pev/fundament als/index.page.

9. What are the financial benefits of owning an electric vehicle on website http:// www. pge.com / en / myhome / saveenergymoney / pev / fundamentals/index.page.

10.Website http://www.drive.com.au/motor-news/tesla-unveils-australiansupercharger-network-20141209-123ob4.html.

11.Environmental Benefits of Electric Vehicles http://www.gumtree.com.au/ scam-security-centre/buying-on-gumtree/the-ultimate-electric-cars-buyingguide.

\section{AUTHORS PROFILE}

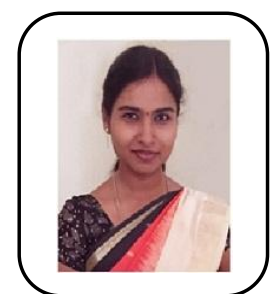

Dr. D. SHARMILA, B.E, M.E, Ph.D., is an Associate Professor in the Department of Electronics and Communication Engineering at R.M.D Engineering College. She has completed her B.E. Degree in Electronics and Communication Engineering and M.E Degree in VLSI Design. She has completed Ph.D in the area of VLSI under Anna University in the year 2018. She is the First Rank holder in M.E degree. She has 20.4 years of teaching experience to UG classes and has guided many B.E. projects. She is the Coordinator for Automotive Electronics Centre of Excellence. She has published three papers in international journals, two papers in International conferences and four papers in national conferences. She has organized one national conference and one national workshop. She has attended four national seminars and four faculty development programs. She is a life time member of IEANG and ISTE. Her areas of Interest include Microprocessor, Networks and VLSI.

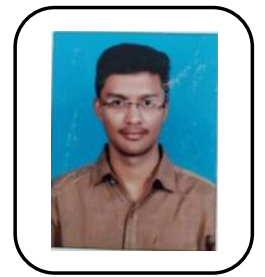

I am VEMULA VENKATA SAI PRAVEEN KUMAR studying at R.M.D. Engineering College. I am kind a person who always see things from a different perspective, thinking of new ideas, learning from my mistakes, all these are the major uplifting things that motivate me every second. I always update myself with the present technologies checking for optimizations if needed and if that is the case needed, I use to work on it for the better result. At present, I am working on the wireless charging of electric vehicles for decreasing range anxiety and increasing the efficiency of the battery. I am determined in my work. I love learning things working with a positive attitude and never try to give up until I get something right. 